\title{
CEMENT-WITHIN-CEMENT REVISION HIP
}

\section{ARTHROPLASTY}

\author{
J. R. LiEberman, B. H. MOECKEl, B. G. EVANS, E. A. SAlvati, C. S. RANAWAT
}

From The Hospital for Special Surgery, New York, USA

\begin{abstract}
We reviewed 19 revision hip arthroplasties in which the new femoral component had been recemented into the old, intact cement mantle. The mean time from the first operation to revision was 64 months and the average follow-up was 59 months. There were 7 excellent, 11 good, and one fair result. No femoral component had been revised for loosening and all the stems appeared radiographically stable. Complications included intraoperative perforation of the femur on two occasions and one dislocation.

The use of the cement-within-cement technique requires that the old cement surface be dry and roughened to increase the surface area and that the cement be injected in the liquid phase to prevent lamination. The indications for this technique include a broken stem with an intact distal cement mantle, the removal of a femoral component for revision of a loose cup to improve exposure and/or increase offset, recurrent dislocation secondary to component malposition, and debonding of the femoral component within an intact cement mantle.
\end{abstract}

J Bone Joint Surg [Br] 1993; 75-B :869-71.

Received 5 February 1993; Accepted after retision 5 May 1993

In cases of revision total hip arthroplasty in which the cement-bone interface is still intact, the removal of cement may be difficult and is often associated with a high incidence of complications. Eftekhar (1978) recommended recementing a new prosthesis into the old cement mantle and Greenwald, Narten and Wilde (1978) showed in laboratory tests that there is little loss of shear strength when this is done. The technique involved rasping and

J. R. Lieberman, MD, Assistant Professor of Orthopaedic Surgery Department of Orthopaedic Surgery, UCLA School of Medicine, Center for Health Sciences, 10833 Le Conte Avenue, Room 76-134 CHS, Los Angeles, California 90024, USA.

B. H. Moeckel, MD, Orthopaedic Surgeon

7 Amalfi Drive, Cromwell, Connecticut 06416, USA.

B. G. Evans, MD, Fellow in Orthopaedic Surgery

E. A. Salvati, MD, Professor of Orthopaedic Surgery

C. S. Ranawat, MD. Professor of Orthopaedic Surgery

The Hospital for Special Surgery. Cornell University Medical Center, 535 East 70th Street, New York. New York 10021, USA.

Correspondence should be sent to Dr J. R. Lieberman.

(C) 1993 British Editorial Society of Bone and Joint Surgery $0301-620 X / 93 / 6670 \$ 2.00$ drying the surface before applying fresh cement, to increase the interface strength between the old and the new.

We have reviewed a series of revision hip arthroplasties performed in this way.

\section{PATIENTS AND METHODS}

Between 1984 and 1989, we performed 21 revision hip arthroplasties (21 patients) by cementing a new femoral component into an old cement mantle. Two patients were excluded from the study because of inadequate data (one died 18 months after the operation and the other was lost to follow-up after seven months). There remained six men and 13 women; their average age was 65 years (19 to 82). The original diagnosis was osteoarthritis (12), rheumatoid arthritis (3), post-traumatic osteoarthritis (3), and congenital dysplasia of the hip (1). The average time from the first operation to revision was 64 months (1 to 144). The patients' a verage weight was $73 \mathrm{~kg}$ (50 to 106) and their average height $164 \mathrm{~cm}$ (151 to 178).

The reasons for revision were femoral stem fracture with an intact distal cement mantle (5), femoral component removed during revision of a loose acetabular component to improve exposure and/or increase offset (4), debonding of the femoral component in an intact distal cement mantle (3), recurrent dislocation from malposition either of the acetabular component (2) or the femoral component (2), loosening of the acetabular component plus debonding of the femoral component (2), and a fracture of the femur distal to the prosthesis (1).

A number of different femoral stems were used at revisions. These were seven Charnley prostheses (Thackray, Leeds, UK); six custom-made (five Charnley and one Triad); three Triad (Johnson and Johnson, New Brunswick, New Jersey); and three Omnifit (Osteonics, Allendale, New Jersey). Three of the custom-made Charnley prostheses had increased femoral neck anteversion and two had long stems. The custom Triad prosthesis also had a long stem. Six acetabular components were revised using cemented prostheses and two also had Müller rings and bone grafts. In another two cases cementless Harris-Galante cups (Zimmer Inc, Warsaw, Indiana) were used. We performed trochanteric osteotomy in 12 cases. 


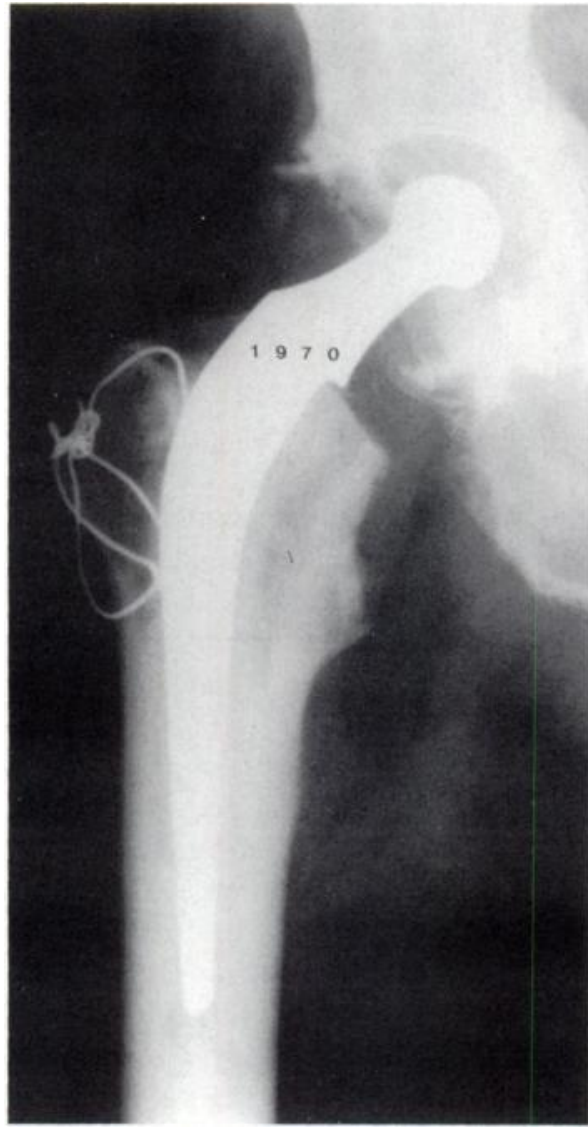

Fig. la

The average follow-up was 59 months ( 24 to 84 ). Clinical evaluation was recorded using The Hospital for Special Surgery (HSS) hip rating system (Salvati and Wilson 1973). Anteroposterior and lateral radiographs were obtained at review and compared with the earliest postoperative radiographs of good quality. Radiolucency around the femoral component was evaluated in the zones described by Gruen, McNeice and Amstutz (1979). Femoral fixation was assessed according to the criteria of Harris and McGann (1986) and fixation of the cemented acetabular components according to the criteria of Harris and Penenberg (1987).

Operative technique. The cement mantle was carefully inspected to make sure that the cement-bone interface was intact. In five patients there was some cracking of the cement proximally, but the distal two-thirds of the cement-bone interface appeared to be well maintained. The proximal cement was curetted out before recementing the new prosthesis.

The superficial layer of the old cement was roughened to increase the surface area and allow room for the new cement and (if possible) a smaller prosthesis of a similar design. Selective removal of cement was used in cases in which the previous stem had been malpositioned, so as to improve the alignment of the new component. Great care was taken to avoid femoral perforation. Finally, the femoral canal was dried and the new cement was injected into the canal in the liquid phase to prevent lamination.

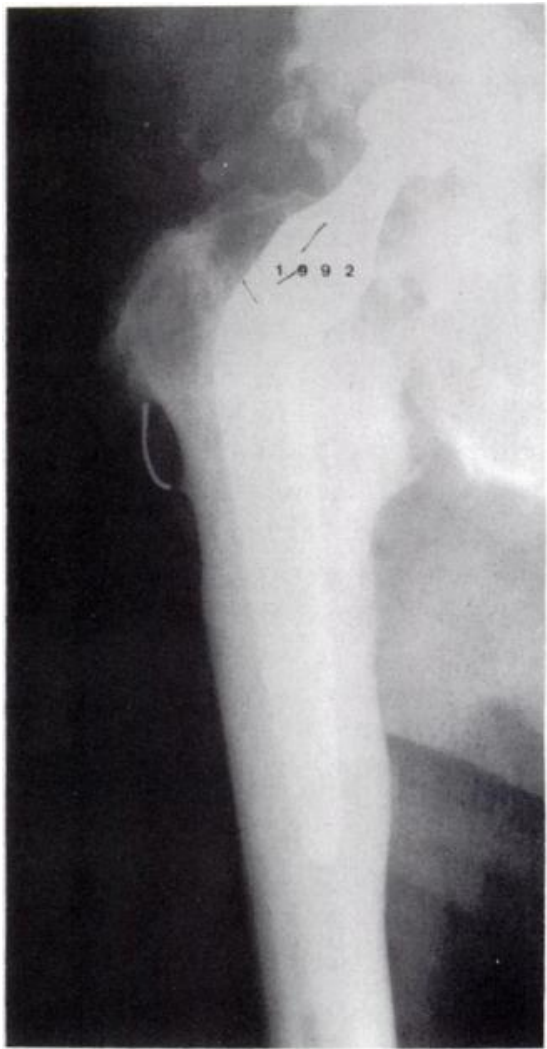

Fig. 10

Revision was performed by the cement-withincement technique and the fixation appeared secure 18 months later 


\section{RESULTS}

No recemented femoral component has required a second revision for loosening and all appeared radiographically stable. One hip had a $3 \mathrm{~mm}$ thick area of focal osteolysis in zone 3 with no evidence of loosening. One cemented acetabular component has been revised for loosening and two other cemented cups appeared possibly loose.

The average preoperative HSS hip score was 20 and the average postoperative score was 31 . Seven hips were rated excellent and 11 good. There was one fair result in a patient whose activity level was limited by spinal stenosis.

Complications included two intraoperative perforations of the femoral cortex and one dislocation. Both perforations were in femora in which the original prosthesis had been placed in valgus. They were small and occurred distally and medially during preparation of the canal. Neither of these hips has been revised. The hip dislocation occurred two months after the revision procedure. The components were well positioned and the hip was braced for two months after reduction. It has since remained stable for 70 months.

\section{DISCUSSION}

The use of the cement-within-cement technique provides a stable femoral reconstruction if there is a sound cementbone interface (Fig. 1). Greenwald et al (1978) showed with cement cylinders in the laboratory that there was only a $6 \%$ reduction in shear strength at the interface between the old cement and the new when compared with the strength of uniform cylinders. It is important that the interface is dry and that the old cement has been rasped.

Recent retrieval studies performed on cemented components further support the use of this technique. Maloney et al (1989), in a retrieval analysis of cemented femoral components, showed the presence of interdigitations between the bone and the cement mantle, with no fibrous tissue interposition, in those cases in which the components appeared stable radiographically. They suggested that debonding of the metallic prosthesis from the surrounding cement mantle with subsequent cement fracture was the sequence of events in prosthetic loosening. Fornasier and Cameron (1976) also showed that failure at the cement-metal interface could cause loosening. If this is the mechanism of loosening of the femoral component it is logical to use the cement-withincement technique in revision surgery.
The indications for this type of revision depend upon the radiographic and intraoperative assessment of the cement-bone interface. Radiolucencies in Gruen zones 1 and 7 , and radiolucency between the cement and the prosthesis proximally, due to debonding, are not contraindications. The proximal cement-bone interface can be readily inspected during the operation.

The technique is contraindicated if there is a fracture of the distal cement mantle or a circumferential radiolucent line at the cement-bone interface consistent with prosthetic loosening. Small radiolucencies, however, may represent only osteoporosis (K wong et al 1992). If, when the cement mantle is roughened, the cement is seen to be loose in the distal part of the femoral canal, the technique should be abandoned.

Although we have only performed cement-withincement revision arthroplasty in a limited number of cases, no further revisions have been required at an average follow-up of nearly five years. In patients with good bone stock the technique offers the surgeon an option other than the laborious and sometimes hazardous removal of an intact cement mantle.

No benefits in any form have been received or will be received from a commercial party related directly or indirectly to the subject of this article.

\section{REFERENCES}

Eftekhar NS. Principles of total hip arthroplasty: St Louis: CV Mosby Co. 1978.

Fornasier VL, Cameron HU. The femoral stem/cement interface in total hip replacement. Clin Orthop 1976: 116:248-52

Greenwald AS, Narten NC, Wilde AH. Points in the technique of recementing in the revision of an implant arthroplasty. $J$ Bone Joint Surg [Br] 1978: 60-B:107-10.

Gruen TA, McNeice GM, Amstutz HC. "Modes of failure" of cemented stem-type femoral components: a radiographic analysis of loosening. Clin Orthop 1979: 141:17-27.

Harris WH, McGann WA. Loosening of the femoral component after use of the medullary-plug cementing technique: follow-up note with a minimum five-year follow-up. J Bome Joint Surg [ Am] 1986: 68-A :1064-6.

Harris WH, Penenberg BL. Further follow-up on socket fixation using a metal-backed acetabular component for total hip replacement: a minimum ten-year follow-up study. J Bone Joint Surg [ Aml] 1987: 69-A:1140-3.

Kwong LM, Jasty M, Mulroy RD, et al. The histology of the radiolucent line. J Bone Joint Surg [Br] 1992: 74-B:67-73.

Maloney WJ, Jasty M, Burke DW, et al. Biomechanical and histologic investigation of cemented total hip arthroplasties: a study of autopsy-retrieved femurs after in vivo cycling. Clin Orthop 1989: 249:129-40.

Salvati EA, Wilson PD Jr. Long-term results of femoral-head replacement. J Bone Joint Surg [Am] 1973: 55-A :516-24. 